\title{
LEARNING AS AN ACTIVITY OF INTERDEPENDENT PEOPLE
}

By

\author{
Ralph Stacey
}

University of Hertfordshire

May 2003

Published in "The Learning Organization" Vol. 10 No 62003

\section{Abstract}

This paper argues that to talk about organisations learning is to reify and anthropomorphise organisations. Instead of thinking of an organisation as if it were a thing or a person it is closer to experience to think of an organisation as the patterning of peoples' interactions with each other. This paper explores the assumptions that are being made when we talk about organisations or groups that learn, or about individuals learning in groups or organisations. It suggests an alternative to thinking in these ways, namely, that learning is an activity of interdependent people. If one takes the view an organisation is the organising activities of interdependent people, it leads to a particular perspective on learning. Much of the communicative and power relating activities of interdependent people take the form of continually iterated patterns of repetition in which meaning and power figurations have the quality of stability which we call identity. But because of the nonlinear iterative nature of human interaction there is always the potential for small differences to be amplified into transformative shifts in identity. Learning is then understood as the emerging shifts in the patterning of human communicative interaction and power relating. Leaning is the activity of interdependent people and can only be understood in terms of self organising communicative interaction and power relating in which identities are potentially transformed. Individuals cannot learn in isolation and organisations can never learn.

Learning, organisation, complexity, process, responsive, emergence.

This paper is one of a number in a special issue titled "The Implications of Complexity and Chaos Theories for Organizations that Learn.” That title immediately points to an important question, which one might pose in the following terms: Do organisations learn or is it individuals and groups in organisations who learn? If one thinks that it is individuals and groups inside an organisation that learn then one focuses attention on individual and collective learning processes. If it is thought that it is organisations that learn then attention is focused on what it is about an organisation that makes learning possible.

A distinction along these lines is used by Easterby-Smith and Araujo (1999) to identify two strands in the literature to do with organisations and learning. They distinguish between the literature on organisational learning and that on the learning organisation. They say that the former "has concentrated on the detached observation and analysis of the processes involved in individual and collective learning inside organizations” (p2). The literature on the learning organisation, on the other hand, is concerned with "methodological tools which can help to identify, promote and evaluate the quality of 
learning processes inside organizations” (p2) and in so doing this literature identifies "templates, or ideal forms, which real organizations could attempt to emulate" (p2). Easterby-Smith et al argue that there is a growing divide between the two strands. Those writing in the organisational learning tradition are interested in "understanding the nature and processes of learning” (p8). Those writing in the tradition of the learning organisation are more interested in "the development of normative models and methodologies for creating change in the direction of improved learning processes” (p8).

Easterby-Smith et al distinguish between a technical and a social strand in the organisational learning literature. The technical strand takes the view that organisational learning is a matter of processing, interpreting and responding to quantitative and qualitative information, which is generally explicit and in the public domain. Key writers in this tradition are Argyris and Schon (1978) with their notions of single and double loop learning. The social strand focuses attention on how people make sense of their work practices (Weick, 1995). This strand utilises Polanyi's distinction between tacit and explicit knowledge (Polanyi \& Prosch, 1975). It focuses attention on the socially constructed nature of knowledge (Brown \& Duguid, 1991), the political processes involved (Coopey, 1995), and the importance of cultural and socialisation processes (Lave \& Wenger, 1991). The literature on the learning organisation also displays technical and social interests. The former tends to focus on interventions based on measurement and information systems, while the latter focuses on individual and group learning processes in a normative manner (Senge, 1991; Isaacs, 1999; Nonaka \& Takeuchi, 1995).

For me, the claim that organisations learn amounts to both reification and anthropomorphism. I argue that organisations are not things because no one can point to where an organisation is - all one can point to is the artefacts used by members of organisations in their work together. In our experience, the organisation qua organisation arises as the patterning of our interactions with each other. I also argue that we depart from our direct experience when we think of the organisation as organism. To sustain the claim that an organisation is in any sense a living organism, we would need to point to where this living body is. Since an organisation is neither inanimate thing nor living body, in anything other than rather fanciful metaphorical terms, it follows that an organisation can neither think nor learn. But the alternative is not all that satisfactory either. To claim that it is only individuals who learn is to continue with the major Western preoccupation with the autonomous individual and to ignore the importance of social processes. One might try to deal with this objection by saying that it is both individuals and groups who learn. But that runs into the same objection as saying that organisations learn. The claim that groups learn is also both reification and anthropomorphism. A group, like any organisation or any other social institution for that matter, is the patterning of peoples' interactions with each other and patterns can neither think nor learn. Furthermore, to talk about individuals who learn in organisations or in groups is also problematic because, once again, this implies that the group and the organisation exist somewhere as a different "place” or "level” to people. If this were not so, how could people be in a group or organisation? This paper explores the assumptions that are being made when we talk about organisations or groups that learn, or about 
individuals learning in groups or organisations. The paper will also suggest an alternative to thinking in these ways, namely, that learning is an activity of interdependent people.

I will be distinguishing, then, between two different ways of thinking about the individual and the group. The first separates individuals and groups as different levels of existence. This splitting of individual and organisation is central to the systems thinking that dominates the literature on learning and organisations. This is essentially a way of thinking in terms of dualisms or dualities. I want to contrast this with a way of thinking in terms of paradox in which individual and group / organisation are aspects of the same processes of interaction between people (Stacey, 2001). This way of thinking is built on the work of G. H. Mead (1934) and Elias (1939). For Mead, mind, self and society arise simultaneously and for Elias, the individual is the singular and the social is the plural of interdependent people. There are then no separate levels, only paradoxical processes of individuals forming the social while at the same time being formed by it. Learning is then to be thought of as the activity of interdependent people.

Colleagues and I (Stacey et al, 2000) have combined the work of Mead, Elias and others with insights from complexity theories to suggest what we have called a complex responsive processes theory of organisations. This paper will review how one might think of learning and organisations from this perspective. We have used some of the work in the complexity sciences as a source domain for analogies with human action, understood from the psychological / sociological theories of Mead and Elias. I will not be referring to chaos theory in this paper for the following reason. In chaos theory the term "chaos" has a precise mathematical meaning. It defines a particular dynamic, the strange attractor, which is a feature of deterministic nonlinear equation operating at certain parameter values. Since chaos is a property of deterministic rather than evolving relationships it cannot have anything to do with learning. Human action is not deterministic - it evolves. By definition that which is deterministic cannot learn. Chaos theory can, therefore, only ever be used as a loose metaphor for anything in the human domain. Some types of complex system simulation do, however, demonstrate the capacity to evolve and it is, therefore, to these that we might turn for analogies with human action.

\section{Dichotomies, dualisms / dualities and paradox}

Consider first the difference between thinking in terms of dualism / dualities as in systems thinking and thinking in terms of paradox as in temporal process thinking (Stacey, 2003).

In thinking about the individual and the group / organisational / social, one immediatley encounters the distinction between the one and the many. One could regard this distinction as a dichotomy, which is a polarised opposition requiring an "either...or" choice. Methodological individualism chooses the "one” side of the polarity, the individual, and from this perspective, learning is the activity of autonomous individuals. Methdological collectivism chooses the "many" side of the polarity and from this perspective, learning is a social phenomenon. There has been a long and unresolved 
debate between these two positions, the upshot of which is the conclusion that it is unsatisfactory to regard the problem of the one and the many, the individual and the social, as a dichotomy.

Another approach, then, is to think in terms of a dualism or a duality. This mode of thinking has a "both...and" structure. Instead of choosing between the "one" and the "many", one keeps both but locates them in different spaces or times. It is this dualistic apprach that dominates thinking about learning and organisations. On the one hand, the individual (the "one”) is thought of as an autonomous individual, where mind is "inside" that person. Mind is then thought of as an "internal world" consisting of representations, maps and models of what is "outside" the person. In other words, mind is thought of as a whole or system of interacting parts contained within a boundary. The actions of a person are selected by this system, part of which the individual is aware of (explicit) and part of which the individual is not aware of (tacit). On this basis, individual learning is thought of as changes in mental models, both tacit and explicit. A particular form of causality, usually not stated explicitly, is implied in this way of thinking. It is assumed that individual human action is caused by the objectives and plans the individual chooses on the basis of his or her mental model and learning is the rational action of choosing to change the mental model and so the action. Causality here takes a rationalist form (Stacey at al, 2000).

When the "one" is thought of in these terms, there is no option but to think of the "many", (group, organisation and society) as a system existing "outside” the individual. This system is then thought of as a bounded entity consisting of individuals who are its parts. The system is formed by the interaction of the individuals and exists at a higher level than the individuals, following laws of its own, which might be thought of as emergent properties. Process has a particular meaning here - it is the interaction of individuals to create an entity outside of themselves. It is then easy to think of such an entity as a thing, a kind of super-individual with its own mind and intentions, even a living entity with a life of its own. From this perspective it is not problematic to think of an organisation as able to learn, where learning is understood as changes in organisational routines and strategies. Organisational learning becomes a form of cultural development and the task becomes one of identiying the organisational features that enable or obstruct such cultural development or organisational learning. It becomes the province of leaders to identify the vision or mission according to which the organisation and its culture should develop. The powerful design the system according to which they an other members of the organisation should interact. The powerful are supposed to make the choices acording to which the organisation, an objective reality outside of them, is to develop. They are to enfold what is to be unfolded by the development of the organisation. This immediately implies a particular form of causality, which is again not usually made explicit. That causality is formative in the sense that it is the process of delopment which is formring the organisation in the sense of unfolding what is already enfolded into it.

The difference between dichotomies and dualisms / dualities is immediately apparent. Unlike the thinking in dochotomies, the way of thinking outlined in the last two 
paragraphs does not choose between idividual and social. It locates them in different "spaces" and then posits a connection between them. Individuals form the social system through their choces of its objectives and the design of interactions between individuals and then the social system affects the actions of those individuals who are parts of the organisational system. The result is a dual causality. There is both the rationalist causality of the choosing individuals and the formative causality of the system that they are parts of. Thinking in this way naturally leads people to look for the features of an organisation, such as teamwork, that enable or block the learning of individuals. However, while thinking in terms of dualisms / dualities is different to thinking in terms of dichotomies in the way just described, they are similar in another respect. The "either...or" thinking of dichotomies and the "both... and" thinking of dualisms / dualities both satisfy a precept of Aristotelian logic, which requires the elimination of contradictions, such as the one and the many, forming and being formed by at the same time, because they are a sign of faulty thinking.

As an alternative to thinking in terms of dichotmies and in terms of dualisms / dualities, one could think of the problem of the one and the many as a paradox. There are a number of different definitions of a paradox. First, it may mean an apparent contradiction, a state in which two apparently conflicting elements appear to be operating at the same time. Paradox in this sense can be removed or resolved by choosing one element above the other all the time or by reframing the problem to remove the apparent contradiction. There is little difference between paradox in this sense and dualism / dualities and this is the meaning of paradox that is usually taken up in the literature on systemic views of organisations. However, paradox may mean a state in which two diametrically opposing forces / ideas are simultaneously present, neither of which can ever be resolved or eliminated. There is, therefore, no possibility of a choice between the opposing poles or of locating them in different spheres. Instead, what is required is a different kind of logic, such as the dialectical logic of Hegel. In this kind of logic, the word paradox means the presence together at the same time of contradictory, essentially conflicting ideas, none of which can be eliminated or resolved. Indeed it is this conflict that gives rise to the transformation that is central to Hegels' dialectical logic. A technical example of this is the concept of mathematical chaos. Here chaos is a dynamic, a pattern, that is stable and unstable at the same time. In this dynamic, stability and instability are inseparable - what we have is the paradox of stable instability or unstable stability. The contradiction between stable and unstable has not been resolved but rather transformed into a different dynamic in whih the meanings of stability and instability have been transformed. The causality implied in this kind of dialectical logic is transformative. However, this is only a rather dry technical example of the dialectical logic. Essential to Hegel's dialectical logic is its social dimension.

Hegel held that one cannot begin, as Kant had done, with an isolated individual subject experiencing the world and then ask how a world of experience gets built up out of the inner world of purely subjective experience. Rather, one must begin with an already shared world of subjects making judgements in the light of possible judgments by others. Hegel accorded central importance to recognition, linking it to desire, particularly the desire for desire of the other. It is through mutual recognition that individuals sustain 
patterns of entitlements and commitments, the social, and it is in the social that the knowing subject, mind, emerges. Hegel emphasised the historical specificity of human self-conceptions upon which society is founded. Person and subject are given content only by the social institutions in which each individual achieves social identity through interdependence and mutual recognition. So, for Hegel, mind or consciousness is manifested in social institutions, that is, ways of life, which give identities, self concepts, to individuals. Here, then, the "one" and the "many" are neither dichotomies nor dualisms / dualities, but poles of a paradox which are transformed into both individual identity / consciousness and social relations at the same time. It is in this tradition that Mead argues that mind, self and society arise together at the same time and Elias argues that the individual is the singular and the social is the plural of interdependent people.

\section{What is an organisation?}

If one takes this paradoxical, dialectical perspective, then how does one think about the nature of a group, organisation or society? Mead (1934) explains the simultaneous emergence of mind and society in terms of the social act in which one gestures to another and in so doing calls forth a response from that other. Gesture and response are inseparable phases in one act which constitutes meaning. Here meaning does not lie in the gesture alone because the meaning of the gesture cannot be known until there is a response. If one person shouts this means aggression if the other responds with an angry shout but it could mean a warning if the other takes evading action. Consciousness arises when the one making a gesture calls forth in herself a similar response to that called forth in the one to whom she is gesturing. She can then know what she is doing. Mead calls this social act a significant symbol. A conversation of gestures in significant symbols make possible far more sophisticated forms of cooperation, of society, because those interacting can know what they are doing and signal to others what they intend. Mead points to the particular importance of the vocal form significant symbol, namely language, in human interaction. Mind is arising at the same time as human social interaction is arising on the conversation of significant symbols. Mind takes the form of a private role play / silent conversation of the gesturer and of the responder. Mind is the process of an individual body gesturing and responding to itself at the same time as it is gesturing and responding to others, the social. Mind and society are therefore simply different aspects of the same processes of communicative interaction in which meaning is arising. Interdependent individuals are interacting with each other in a way in which they are taking the attitudes of others, of the group and of society as a whole, to their gestures. They are also interacting in a way in which they are taking the attitude of the group or society to themselves. As subjects (the "I") they are taking themselves as objects (the "me" or attitude of the society to the "I") and it is in this process that self-consciousness arises.

What Mead is explaining here are processes of communicative interaction that constitute both mind and society at the same time. They are simultaneously forming and being formed by each other at the same time. One is not at a different level to another and it makes no sense to think of one inside the other. Instead of thinking in terms of spatial 
metaphors, of levels and inside-outside, Mead's explanation focuses our attention on how the actions of human bodies are creating patterns of meaning in their iterated interaction with each other. As people interact, coherent patterns of meaning, of knowledge, are perpetually iterated. These continually emerging patterns take thematic forms, both narrative and propositional, both conscious and unconscious, and they organise the experience of being together. Such themes are iterated in the repetitive form of habit but always with the potential for transformation. Such patterns are patterning themselves in the local interaction between people, a point to be explained later in relation to complexity theory. The result is a way of thinking about human action that moves away from the dual rationalist-formative causality referred to above to a transformative causality (Stacey, Griffin \& Shaw, 2000).

This is a key aspect of what colleagues and I have called complex responsive processes. Organisations are patterns of communicative interaction between interdependent individuals. Another key aspect of complex responsive processes of human relating is to be found in the work of Elias (2000).

For Elias, all human relating imposes constraints on those relating, while at the same time enabling those relating to do what they could not otherwise have done. This is, of course, what power means - power is enabling constraints between people. Instead of thinking of power as the possession of some and not of others, Elias understands power as a characteristic of, a pattern in, all human relating. In human relating some are more constrained than others so establishing a figuration of power relations in which the distribution of power is not equal. As they interact, the power relations, the pattern of enabling constraints, emerges, shifts and evolves. Elias describes in some detail how ideologies unconsciously sustain figurations of power relations. He also connects emerging and iterated patterns of power relations with identity. Power figurations operate to include some people in a group and exclude others in the interest of sustaining power relations and in the course of doing this, powerful group identities are created. Elias calls these "we" identities and shows how inextricably linked such "we" identities are to each individual's "I” identity.

These closely connected aspects of power relations, ideology and identity are also key aspects of complex responsive processes of relating between human bodies.

Organisations are patterns of power relations sustained by ideological themes of communicative interaction and patterns of inclusion and exclusion in which human identities emerge. There is yet another key element in the theory of complex responsive processes. This is provided by analogies drawn from particular kinds of computer simulation to be found in what has come to be called the sciences of complexity. The simulations model the dynamics of iterated, nonlinear interaction between entities. These simulations) reveal some abstract properties of interaction between digital symbols. An agent in the simulations is an algorithm, that is, a string of digital symbols. When these agents are sufficiently different to each other and when they are sufficiently connected to each other, then the simulations display the capacity to evolve in novel, unpredictable ways (for example, see Allen, 1998a, 1998b; Ray, 1992; Kauffman, 1995). What the simulations are demonstrating is that it is quite possible that widespread, coherent pattern 
will emerge from the local interaction between agents. Widespread coherent, evolving patterns emerge from local interaction in the complete absence of an overall blueprint plan or programme. This process is termed self-organisation, which can be understood as interaction patterning itself from within, as it were. When the interacting agents are different enough from each other, then nonlinear iteration can amplify these differences into novel widespread pattern. The pattern of interaction here is transforming itself from within. These properties provide an abstract analogy for human interaction if translated into the human domain using suitable theories of psychology and sociology to provide the attributes of being human.

A key aspect of complex responsive process of human relating is their self-organising emergent nature in which communicative interaction and power relating patterns itself. The causality is transformative and there is nothing above or below interaction itself that is causing the coherent patterning. Organisations are then self-organising patterns of communicative interacting and power relating between human bodies in the living present. In the living present, individuals are interacting with each other in their own local situations. The basis of their action is their current expectations of the future, conditioned by their accounts of the past, where those accounts of the past are influencing expectations for the future and expectations of the future are influencing the current accounts of the past. This view of organisation focuses attention on the way in which ordinary everyday conversations between people are perpetually creating the future, in the present, in the form of shifting patterns of communication and power relations. What is being perpetually created is nothing other than inseparable individual and collective identities. Organisations are then self-organising patterns of conversation, of meaning, in which human identities emerge.

To summarise, the argument presented in this section leads to the conclusion that an organisation is the thematically patterned activities of interdependent people, which constitute their closely interconnected individual and collective identities.

\section{Complex responsive processes of learning}

If one takes the view presented above on the nature of an organisation as the organising activities of interdependent people, it leads to a particular perspective on learning. Much of the communicative and power relating activities of interdependent people take the form of continually iterated patterns of repetition in which meaning and power figurations have the quality of stability which we call identity. But because of the nonlinear iterative nature of human interaction there is always the potential for small differences to be amplified into transformative shifts in identity. Learning is then understood as the emerging shifts in the patterning of human communicative interaction and power relating. Learning is emerging shifts in the thematic patterning of human action. Another way of saying this is to say that learning is the emerging transformation of inseparable individual and collective identities. Learning occurs as shifts in meaning and it is simultaneously individual and social. Leaning is the activity of interdependent people and can only be understood in terms of self organising communicative interaction 
and power relating in which identities are potentially transformed. Individuals cannot learn in isolation and organisations can never learn.

The immediate implication of such a view of the nature of learning is that it will inevitably give rise to anxiety. This is because the experience of challenges to, and shifts in one's individual-collective identities are existentially threatening. It becomes important then to pay particular attention to how people respond to anxiety because defensive ways of dealing with anxiety inevitably close down learning processes. Also of great importance is that transformative learning involves moving into the unknown. People cannot know in advance what patterns of identity they are moving to and moving into the unknown in this way can easily be seen by others to be incompetence. In a social order that greatly prizes competence, understood as knowing, it is deeply shaming not to know. The social process of shame (Aram, 2001) is thus inextricably involved in learning processes and it becomes important to understand how people respond to the potential for shame.

\section{References}

Aram E. (2001), The Experience of Complexity: Learning as the potential transformation of identity, unpublished thesis: University of Hertfordshire.

Allen, P. M. (1998a), “Evolving complexity in social science”, in Altman, G. \& Koch, W. A. (Eds.), Systems: New Paradigms for the Human Sciences, Walter de Gruyter, New York.

Allen, P. M. (1998b), “Modeling complex economic evolution”, in Schweitzer, F. \& Silverberg, G. (Eds.), Selbstorganisation, Dunker and Humblot, Berlin.

Argyris, C. \& Schon, D. (1978), Organizational Learning: A Theory of Action Perspective, Addison-Wesley, Reading, MA.

Brown, J. S. \& Duguid, P. (1991), “Organizational learning and communities-of-practice: toward a unified view of working, learning and innovation”, Organization Science Vol 2 No 1, pp40-56.

Coopey, J. (1995), “The learning organization: power, politics and ideology”, Management Learning”, Vol 29 No 3, pp193-214.

Elias, N. (1939), The Civilizing Process, Blackwell, Oxford.

Easterby-Smith, M. \& Araujo, L. (1999), “Organizational learning: current Debates and opportunities”, in Easterby-Smith, M., Burgoyne, J. \& Araujo, L. (Eds.), Organizational Learning and the Learning Organization, Sage, London. 
Isaacs, W. (1999), Dialogue and the art of thinking, Doubleday, New York.

Kauffman, S. A. (1995), At Home in the Universe, Oxford University Press, New York.

Lave, J. \& Wenger, E. (1991), Situated Learning: Legitimate peripheral participation, Cambridge University Press, New York.

Mead, G. H. (1934), Mind, Self, \& Society: From the Standpoint of a Social Behaviorist, Chicago, University Press Chicago.

Nonaka, I. \& Takeuchi, H. (1995), The Knowledge-Creating Company: How Japanese Companies Create the Dynamics of Innovation, Oxford University Press, Oxford.

Polanyi, M. and Prosch, H. (1975), Meaning, The University of Chicago Press, Chicago.

Ray, T. S. (1992), "An approach to the synthesis of life”, in Langton, G. C., Taylor, C., Doyne Farmer, J. \& Rasmussen, S. (Eds.), Artificial Life II, Santa Fe Institute, Studies in the Sciences of Complexity, vol. 10, Addison-Wesley, Reading, MA.

Senge, P. M. (1990), The Fifth Discipline: The Art and Practice of the Learning Organization, Doubleday, New York.

Stacey, R. D., Griffin, D. \& Shaw, P. (2000), Complexity and Management: fad or radical challenge to systems thinking, Routledge, London.

Stacey, R. D. (2001), Complex Responsive processes in organizations: learning and knowledge creation, Routledge, London.

Stacey, R. D. (2003), Strategic Management and Organisational Dynamics: the challenge of complexity, Pearson Education, London. ( $4^{\text {th }}$ Edition)

Weick, K. (1995), Sensemaking in Organizations, Sage, Thousand Oaks CA. 